\title{
COMPARATIVE EVALUATION OF ANTIOXIDANT ACTIVITY OF SUBSTITUTED FLAVONES
}

\author{
HELEN WILLIAM ${ }^{1 *}$, NARAYANAN N²
}

${ }^{1}$ Department of BioTechnology, Periyar Maniammai University, Thanjavur, Tamil Nadu, India. ${ }^{2}$ Department of Pharmacy, Jaya College of Pharmacy, Thiruninravur, Chennai, Tamil Nadu, India. Email: helenwilliam@gmail.com

Received: 06 April 2017, Revised and Accepted: 31 July 2017

ABSTRACT

Objective: The flavonoids are a heterogeneous group of plant polyphenols that are endowed with several biological activities including antioxidant, anti-inflammatory, immunomodulatory, antiviral, antimutagenic, and anticarcinogenic properties. They are believed to interfere with the various free radical-producing systems and they also enhance the functions of endogenous antioxidants. The aim of this study was to compare the antioxidant activity of synthesized substituted flavones by various free radical scavenging assays.

Methods: The flavones used in the study, 6,3',4' - trihydroxy flavones (THF) and 3-hydroxy-6,3'-dimethoxy flavones were synthesized using standard procedures and their antioxidant activity was compared by 2,2-diphenyl-1-picrylhydrazyl (DPPH) assay, hydrogen peroxide scavenging assay, hydroxyl radical scavenging assay, reducing power capacity, superoxide free radical scavenging assay, and 2,2'-azino-bis-3-ethylbenzthiazoline-6sulphonic acid assay.

Results: In the DPPH assay, THF has an inhibitory concentration $50 \%$ value of $18.89 \mu \mathrm{g} / \mathrm{ml}$ which was much better than that of standard ascorbic acid which was $26.1 \mu \mathrm{g} / \mathrm{ml}$. The THF had a much better antioxidant activity in most of the free radical scavenging assays.

Conclusion: From the study, it can be seen that the flavones showed significant antioxidant activity that can be used for treatment of various diseases.

Keywords: Flavones, Antioxidant activity, Inhibitory concentration $50 \%$ value.

(C) 2017 The Authors. Published by Innovare Academic Sciences Pvt Ltd. This is an open access article under the CC BY license (http://creativecommons. org/licenses/by/4. 0/) DOI: http://dx.doi.org/10.22159/ajpcr.2017.v10i11.18973

\section{INTRODUCTION}

Flavonoids are a group of natural substances, found in fruits, vegetables, flowers, tea, wine, etc. [1]. They have a common phenylbenzopyrone structure and are broadly classified into flavones, flavanols, flavonols, flavanones, flavanonols, and isoflavones [2,3]. They are essential components of various pharmaceutical, medicinal, and cosmetic preparations owing to their antioxidant, anti-inflammatory, anticarcinogenic, and various other miscellaneous activities [4]. At present, they are more widely investigated for their potent antioxidant and free radical scavenging activities [5]

An antioxidant inhibits the oxidation of other molecules. Oxidation reactions produce free radicals, which can start chain reactions in cells, ultimately resulting in cell damage or death. The mechanism of action of antioxidants is to terminate the chain reactions, either by removing the free radical intermediates or inhibiting other oxidative reactions $[6,7]$

Flavonoids are powerful antioxidants against free radicals and are often described as free-radical scavengers [8]. This activity of flavonoids is due to their hydrogen-donating ability. The phenolic groups of flavonoids are a source of readily available " $\mathrm{H}$ " atoms so that the subsequent radicals produced can be delocalized over the flavonoid structure [9]. Since most of the scientific reports are on the natural flavonoids, the present work was undertaken to determine whether the synthetic flavonoids also possess significant antioxidant activity.

\section{METHODS}

The flavones used in the study, 6,3', ' - trihydroxy flavones (THF) (sample 1) and 3-hydroxy-6,3'-dimethoxy flavones (DMF) (sample 2) were synthesized using standard procedures at Research Organics, Chennai, Tamil Nadu. The melting point, ultraviolet (UV), infrared, and nuclear magnetic resonance data of the synthesized compounds were compared with standard samples.
The comparative antioxidant activity of the synthesized flavones was evaluated by the following methods.

2,2-diphenyl-1-picrylhydrazyl (DPPH) radical scavenging activity DPPH is a stable free radical widely used to evaluate the radical scavenging activity of antioxidant compounds. The method is based on the reduction of DPPH, in the presence of hydrogen-donating antioxidant, due to the formation of non-radical from DPPH-H [10].

The radical scavenging activity of the samples was determined using DPPH assay according to Chang et al. The decrease in the absorption of the DPPH solution after the addition of an antioxidant was measured at $517 \mathrm{~nm}$. Ascorbic acid was used as reference $(10 \mathrm{mg} / \mathrm{ml}$ dimethyl sulfoxide [DMSO]). Different volumes (1.25-20 $\mu \mathrm{l})$ of samples were made up to $40 \mu \mathrm{l}$ with DMSO and $1.48 \mathrm{ml}$ DPPH $(0.1 \mathrm{mM})$ solution was added. The reaction mixture was incubated in dark condition at room temperature for 20 minutes. After 20 minutes, the absorbance of the mixture was read at $517 \mathrm{~nm} .3 \mathrm{ml}$ of DPPH was taken as control [11].

Calculation

$\%$ inhibition $=\frac{\text { Control-test }}{\text { Control }} \times 100$

\section{Hydroxyl radical scavenging activity}

This assay is based on the quantification of the degradation product of 2 deoxyribose by condensation with thiobarbituric acid (TBA). Hydroxyl radical was generated by the $\mathrm{Fe}^{3+-}$ ascorbate- EDTA $-\mathrm{H}_{2} \mathrm{O}_{2}$ system (the Fenton reaction). The reaction mixture contained 2 deoxy 2 ribose, $\mathrm{KH}_{2} \mathrm{PO}_{4}-\mathrm{KOH}$ buffer, $\mathrm{FeCl}_{3}$, EDTA, $\mathrm{H}_{2} \mathrm{O}_{2}$, ascorbic acid and various concentrations $(0-200 \mu \mathrm{g} / \mathrm{ml})$ of the test sample. After incubation for $1 \mathrm{hr}$ at $37^{\circ} \mathrm{C}, 0.5 \mathrm{ml}$ of the reaction mixture was added to $1 \mathrm{ml}$ of $2.8 \%$ 
trichloroacetic acid, then $1 \mathrm{ml}$ aqueous TBA was added, and the mixture was incubated at $90^{\circ} \mathrm{C}$ for 15 minutes to develop the color. After cooling, the absorbance was measured at $532 \mathrm{~nm}$ against an appropriate blank solution [12]. The absorbance was measured using the abovementioned formula.

\section{Reducing power activity}

The reducing power of the samples was determined by the following method. Different sample concentrations were mixed with $2.5 \mathrm{ml}$ of phosphate buffer (pH 6.6) and $2.5 \mathrm{ml}$ of $1 \%$ potassium ferric cyanide was added and boiled for 20 minutes at $50^{\circ} \mathrm{C}$. After incubation, $2.5 \mathrm{ml}$ of $10 \%$ trichloroacetic acid were added to the mixtures followed by centrifugation at $2000 \mathrm{rpm}$ for 10 minutes. The upper layer $(5 \mathrm{ml})$ was mixed with $5 \mathrm{ml}$ of distilled water and $1 \mathrm{ml}$ of $0.1 \%$ ferric chloride and the absorbance was read at $700 \mathrm{~nm}$ [13].

\section{Hydrogen peroxide scavenging assay}

The ability of the samples to scavenge hydrogen peroxide was determined according to following method. $40 \mathrm{mM}$ solution of hydrogen peroxide was prepared in phosphate buffer ( $\mathrm{pH} 7.4$ ). Various concentrations of samples were added to $0.6 \mathrm{ml}$ of $\mathrm{H}_{2} \mathrm{O}_{2}$ solution. The absorbance was measured at $230 \mathrm{~nm}$ after 10 minutes, against a blank solution containing the phosphate buffer without hydrogen peroxide [14] and the percentage inhibition was calculated as per the aforesaid formula.

\section{Superoxide free radical scavenging activity}

Superoxide is biologically important as it can form singlet oxygen and hydroxyl radical. Superoxide anion radical formation contributes to redox imbalance, resulting in harmful physiological consequences. The oxidation of NADH generates superoxide anion in the riboflavin-NADH system, which is assayed by the reduction of nitro-blue tetrazolium (NBT) resulting in the formation of a blue formazan product. $0.02 \mathrm{ml}$ of sample, $0.05 \mathrm{ml}$ of riboflavin, $0.2 \mathrm{ml}$ of EDTA solution, and $0.1 \mathrm{ml}$ NBT solution were mixed in test tube and reaction mixture was diluted up to $2.64 \mathrm{ml}$ with phosphate buffer. The absorbance of solution was measured at $560 \mathrm{~nm}$ using DMSO as blank after illumination for 5 minutes and difference in OD was determined after 30 minutes incubation in fluorescent light. Absorbance was measured after illumination for 30 minutes at $560 \mathrm{~nm}$ on UV visible spectrophotometer and the percentage inhibition was calculated as per the aforesaid formula [15].

\section{2,2'-azino-bis-3-ethylbenzthiazoline-6-sulphonic acid (ABTS)} radical scavenging activity

Oxidation of ABTS with potassium per sulfate (a blue chromogen) generates the preformed radical monocation of ABTS, which is reduced in the presence of hydrogen-donating antioxidants.

- Solution I: $20 \mathrm{mM}$ solution of ABTS is prepared using water.

- Solution II: $17 \mathrm{mM}$ solution of potassium per sulfate, is prepared using water.

$0.3 \mathrm{ml}$ of solution II was added to $5 \mathrm{ml}$ of solution I and the reaction mixture was left to stand at room temperature overnight in dark before use.

$1 \mathrm{ml}$ of distilled water was added to $0.2 \mathrm{ml}$ of various concentrations of the samples, and $0.16 \mathrm{ml}$ of ABTS solution was added and make up to the final volume of $1.36 \mathrm{ml}$. Absorbance was measured after 20 minutes at $734 \mathrm{~nm}$ and the percentage inhibition was calculated as per the aforementioned formula [16].

\section{RESULTS AND DISCUSSION}

\section{DPPH radical scavenging activity}

DPPH is a stable free radical with pink which turns yellow when scavenged. Antioxidants react with DPPH and reduce it to DPPH-H, and as a consequence the absorbance decreases. The degree of discoloration indicates the scavenging potential of the antioxidant compounds or extracts in terms of hydrogen donating ability (Fig. 1 and Table 1).

From the graph, it can be seen that THF has an inhibitory concentration $50 \%\left(\mathrm{IC}_{50}\right.$ ) value of $18.89 \mu \mathrm{g} / \mathrm{ml}$ which was much better than that of standard ascorbic acid which was $26.1 \mu \mathrm{g} / \mathrm{ml}$.

\section{Hydroxyl radical scavenging activity}

Hydroxyl radical is one of the most potent reactive oxygen species in the biological system that reacts with polyunsaturated fatty acid moieties of cell membrane phospholipids and causes damage to cell. Scavenging of hydroxyl radical of different extracts is presented in Fig. 2. From the data, it can be seen that THF has more activity comparable to that of standard (Table 2).

\section{Reducing power activity}

This method is based on the principle of increase in absorbance of the reaction mixture. Increase in the absorbance indicates increase in the antioxidant activity. Here, the antioxidant forms a colored complex with potassium ferricyanide, trichloroacetic acid, and ferric chloride which is measured at $700 \mathrm{~nm}$. Increase in absorbance of the reaction mixture indicates reducing power of sample (Fig. 3).

Comparative reducing power capacity of different flavones with their standard.

Both flavones exhibited significant reducing power activity, but 6, 3', 4'TMF was exhibiting better reducing activity.

Table 1: IC $_{50}$ values of different flavones in DPPH radical scavenging assay

\begin{tabular}{ll}
\hline Sample/standard & IC $_{50}(\boldsymbol{\mu g} / \mathbf{m l})$ \\
\hline Ascorbic acid (standard) & 26.107 \\
THF (sample 1) & 18.89 \\
DMF (sample 2) & 268.07 \\
\hline
\end{tabular}

$\mathrm{IC}_{50}$ : Inhibitory concentration 50\%, DPPH: 2,2-diphenyl-1-picrylhydrazyl, THF: 6,3',4' - trihydroxy flavones, DMF: 3-hydroxy-6,3'-dimethoxy flavones

Table 2: $\mathrm{IC}_{50}$ values of different flavones in hydroxyl scavenging assay

\begin{tabular}{ll}
\hline Sample/standard & IC $_{\mathbf{5 0}}(\boldsymbol{\mu g} / \mathbf{m l})$ \\
\hline Ascorbic acid (standard) & 947.39 \\
THF (sample 1) & 991.62 \\
DMF (sample 2) & 1215.80 \\
\hline
\end{tabular}

$\mathrm{IC}_{50}$ : Inhibitory concentration 50\%, THF: 6,3',4' - trihydroxy flavones, DMF: 3-hydroxy-6,3'-dimethoxy flavones

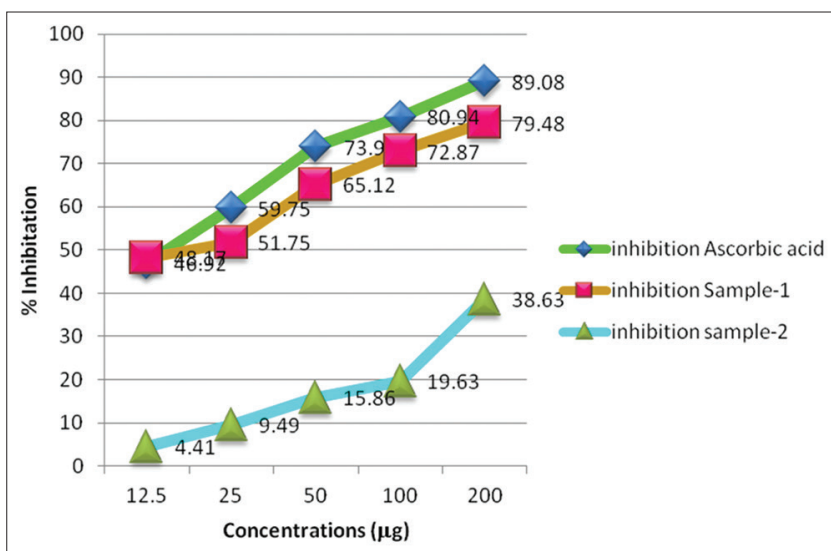

Fig. 1: 2,2-diphenyl-1-picrylhydrazyl radical scavenging activity 
Table 3: $\mathrm{IC}_{50}$ values of different flavones in hydrogen peroxide scavenging assay

\begin{tabular}{ll}
\hline Sample/standard & IC $_{50}(\boldsymbol{\mu g} / \mathbf{m l})$ \\
\hline Ascorbic acid (standard) & 731.77 \\
THF (sample 1) & 7117.45 \\
DMF (sample 2) & 1981.74 \\
\hline
\end{tabular}

$\mathrm{IC}_{50}$ : Inhibitory concentration 50\%, THF: 6,3', $4^{\prime}$ - trihydroxy flavones, DMF: 3-hydroxy-6,3'-dimethoxy flavones

Table 4: $\mathrm{IC}_{50}$ values of different flavones in superoxide free radical scavenging activity

\begin{tabular}{ll}
\hline Sample/standard & IC $_{50}(\mu \mathrm{g} / \mathbf{m l})$ \\
\hline Ascorbic acid (standard) & 238.35 \\
THF (sample 1) & 674.79 \\
DMF (sample 2) & 1076.65 \\
\hline
\end{tabular}

IC $_{50}$ : Inhibitory concentration 50\%, THF: 6,3',4' - trihydroxy flavones, DMF: 3-hydroxy-6,3'-dimethoxy flavones

Table 5: IC $_{50}$ values of different flavones in ABTS radical scavenging activity

\begin{tabular}{ll}
\hline Sample/standard & IC $_{\mathbf{5 0}}(\boldsymbol{\mu g} / \mathbf{m l})$ \\
\hline Ascorbic acid (standard) & 941.11 \\
THF (sample 1) & 1147.34 \\
DMF (sample 2) & 235.62 \\
\hline
\end{tabular}

$\mathrm{IC}_{50}$ : Inhibitory concentration 50\%, THF: 6,3', ' - trihydroxy flavones, DMF: 3-hydroxy-6,3'-dimethoxy flavones, ABTS: 2,2'-azino-bis-

3-ethylbenzthiazoline-6-sulphonic acid

\section{Hydrogen peroxide scavenging assay}

Hydrogen peroxide enters into human body through inhalation, eye or skin contact, etc., it is rapidly decomposed into oxygen and water and this may produce hydroxyl radicals that can initiate lipid peroxidation and cause DNA damage in the body. Here, the results indicate both flavones have very less activity when compared to that of the standard (Fig. 4 and Table 3).

\section{Superoxide free radical scavenging activity}

Although superoxide anion is a weak oxidant, it ultimately produces powerful and dangerous hydroxyl radicals as well as singlet oxygen which contribute to oxidative stress. The principle of superoxide free radical scavenging activity is the conversion of highly water soluble NBT salt into NBT diformazan dye upon reduction with superoxide anion. Here, also 6,3'4' TMF-exhibited better scavenging activity while at higher concentrations DMF also showed some activity (Fig. 5 and Table 4).

\section{ABTS radical scavenging activity}

The ABTS radical cation is reactive toward most antioxidants. During this reaction, blue ABTS radical cation is converted to colorless neutral form. The DMF had better activity (Fig. 6 and Table 5).

\section{CONCLUSION}

The synthesized substituted flavones, THF (sample 1), and DMF (sample 2)-exhibited varying degrees of antioxidant activity toward different radical scavenging assays. Relatively better antioxidant activity was shown by THF than DMF, which may be due to the presence of more number of hydroxyl groups on B ring. In addition, the $\mathrm{C}_{2}-\mathrm{C}_{3}$ double bond in conjugation with a 4-oxo function in the $\mathrm{C}$ ring and $\mathrm{OH}$ substitution in the $\mathrm{A}$ ring may play an important role in the antioxidant activity of flavones [17]. Hence, in this study, the compounds demonstrated considerable free radical scavenging activity and could be further evaluated for amelioration

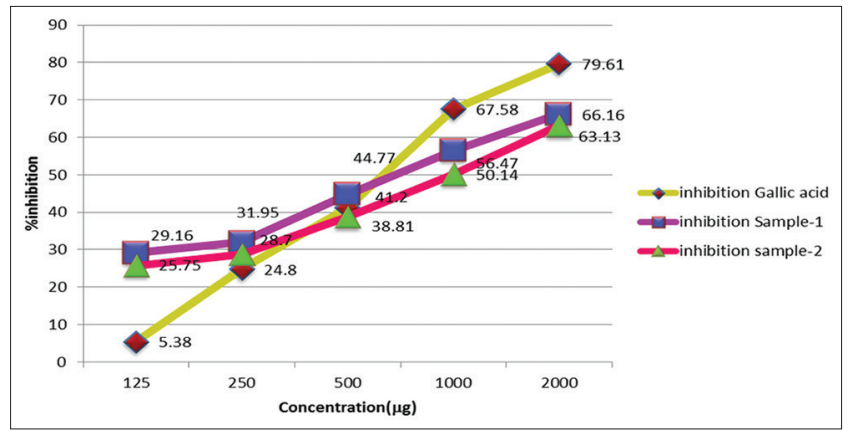

Fig. 2: Hydroxyl radical scavenging activity

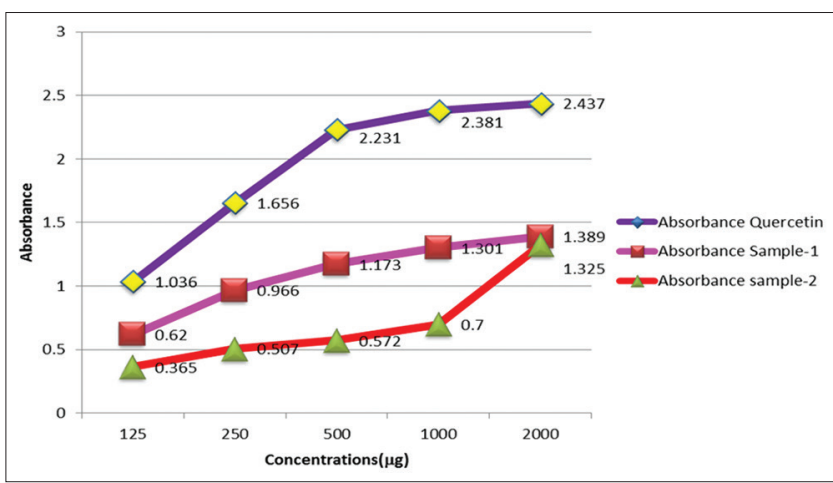

Fig. 3: Reducing power activity

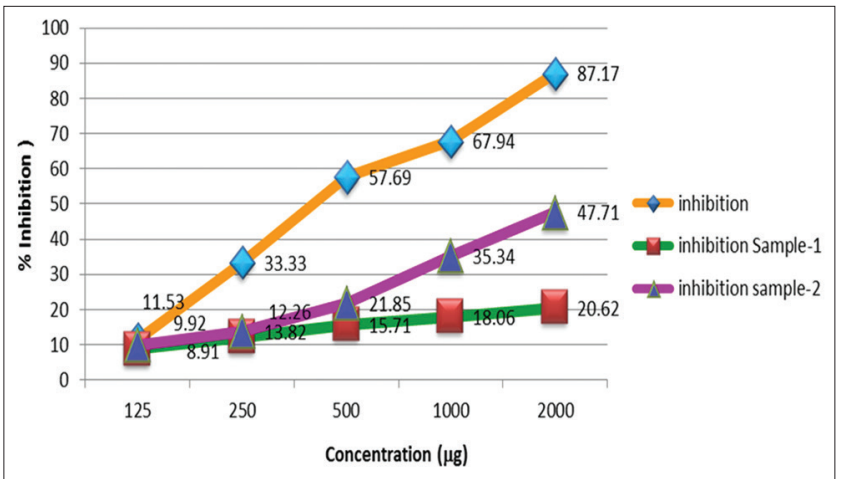

Fig. 4: Hydrogen peroxide scavenging activity

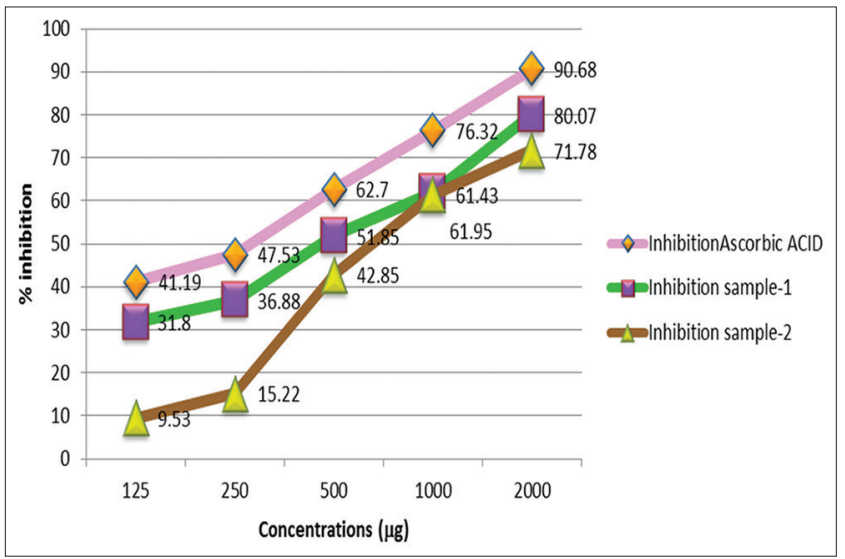

Fig. 5: Superoxide free radical scavenging activity 


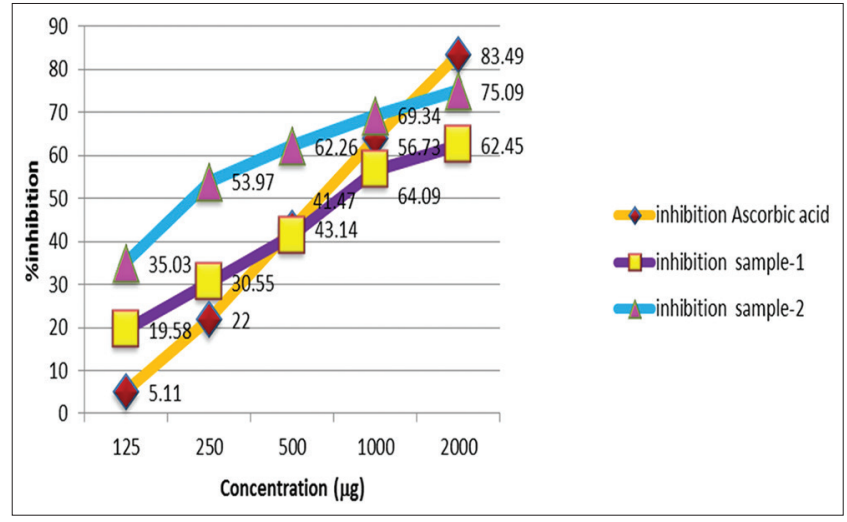

Fig. 6: 2,2'-azino-bis-3-ethylbenzthiazoline-6-sulphonic acid radical scavenging activity

of free radical-mediated diseases such as inflammation, cancer, and neurodegenerative disorders.

\section{REFERENCES}

1. Middleton EJ Jr. Effect of plant flavonoids on immune and inflammatory cell function. Adv Exp Med Biol 1998;439:175-82.

2. Middleton EJ, Kandaswami C. The impact of plant flavonoids on mammalian biology: Implications for immunity, inflammation and cancer. In: Harborne JB, editor. The Flavonoid Advances in Research Since 1986. $1^{\text {st }}$ ed. London: Chapman and Hall; 1994. p. 619-52.

3. Harborne JB, Williams CA. Advances in flavonoid research since 1992. Phytochemistry 2000;55:481-504.

4. Sandhar HK, Kumar B, Tiwari SP, Salhan M, Sharma P. A review of phytochemistry and pharmacology of flavonoids. Int Pharm J
2011;1(1):25-41.

5. Procházková $\mathrm{D}$, Boušová I, Wilhelmová N. Antioxidant and prooxidant properties of flavanoids. Fitoterapia 2011;82(4):513-23.

6. Ames BN, Shigenag MK, Hagen TM. Oxidants, antioxidants and the degenerative disease of aging. Proc Natl Acad Sci 1993;90(7):7915-22.

7. Shenoy K, Shirwaiker A. Anti-inflammatory and free radical scavenging studies of hyptis snravolens. Indian Drug 2002;39:574-7.

8. Pal RS, Ariharasivakumar G, Girhepunjhe $\mathrm{K}$, Upadhay A. In vitro antioxidative activity of phenolic and flavonoids compounds extracted from seeds of Abrus precatorius. Int J Pharm Pharm Sci 2009;1:136-40.

9. Tripoli E, Guardia ML, Giammanco S, Majo DD, Giammanco M. Citrus flavonoids: Molecular structure, biological activity and nutritional properties: A review. Food Chem 2007;104:466-79.

10. Shen Q, Zhang B, Xu R, Wang Y, Ding X, Li P. Antioxidant activity in vitro of selenium-contained protein from the se-enriched Bifodobacterium animalis 01. Anaerobe 2010;16(4):380-6.

11. Chang ST, Wu JH, Wang SY, Kang PL, Yang NS, Shyur LF. Antioxidant activity of extracts from Acasia confusa bark and heartwood. J Agric Food Chem 2001;49(7):3420-4.

12. Kunchandy E, Rao MN. Oxygen radical scavenging activity of curcumin. Int J Pharm 1990;58:237-40.

13. Yen GC, Duh PD. Antioxidant properties of methonolic extracts from peanut hull. J Am Oil Chem Soc 1993;70:383-6.

14. Ruch RJ, Cheng SJ, Klaunig JE. Prevention of cytotoxicity and inhibition of intercellular commuincation by antioxidant catechins isolated from Chinese green tea. Carcinogenesis 1989;10(6):1003-8.

15. Valentao P, Fernandes E, Carvalho F, Andrade PB, Seabra RM, De Lourdes BM. Studies on the antioxidant activity of Lippia citriodora infusion: Scavenging effect on superoxide radical, hydroxyl radical and hypochlorous acid. Biol Pharm Bull 2002;25(10):1324-7.

16. Re R, Pellegrini N, Proteggente A, Pannala A, Yang M, Rice-Evans C. Antioxidant activity applying an improved ABTS radical cation decolorization assay. Free Radic Biol Med 1999;26:1231-7.

17. Taha AH, Sayed AE, Hossam MH, Mona HH. Cytotoxic and antioxidant activities of secondary metabolites from Pulicaria undulata. Int J Pharm Pharm Sci 2016;8(9):150-5. 